\title{
Africa: Media Systems
}

\author{
WINSTON MANO
}

University of Westminster

This entry concentrates on media systems in countries of Sub-Saharan Africa. The SubSaharan media system was born in the colonial era. Following the partition of Africa in Berlin in 1884, the colonial era saw the establishment of mass media systems that initially served minority white settlers located in the emerging urban centers. Both early print and broadcasting frameworks were affected by the different policies and approaches of the colonial powers. The use of European languages, state-biased ownership systems, and limited media freedom are among colonial media attributes that continue today. The national media systems and countries discussed as part of this region are anything but homogeneous because Sub-Saharan Africa is huge and diverse. It covers 42 mainland countries and 6 island nations located south of the Sahara desert. Although the penetration of communication media has picked up in the past 50 years, only radio comes near to being described as a "mass medium."

\section{GENERAL TRENDS}

The spread and access to the mass media in Sub-Saharan Africa has been a highly uneven process. Estimates vary as accurate and up-to-date figures are very hard to find, but development has been rapid in the past 50 years. Among old media, $\rightarrow$ radio has achieved the best penetration owing to its affordability and adaptability. The estimated number of radio sets in Sub-Saharan Africa (excluding South Africa) rose from 460,000 in 1955 to over 70 million in 1995. What is even more remarkable is that there was a tenfold increase in the number of radio sets between 1955 and 1965 and a fourfold increase over the next decade. Sub-Saharan Africa had 158 million radio broadcasting receivers in the late 1990s, up from 33 million in 1970 (Mytton 2000).

Even the largely urban and elitist medium of $\rightarrow$ television has shown remarkable growth in Africa. UNESCO estimated that in 1997 Sub-Saharan Africa had 1,396 million television sets compared to 299 million in 1970 and 749 million in 1985 ( $\rightarrow$ UNESCO). The figures for print media titles published in Sub-Saharan Africa in the late 1990s show at least 224 daily newspapers with a combined circulation of 12 million, a marked increase from 199 newspapers in 1970, which had a combined circulation of just 4 million (World Bank 2006). From 2004 to 2008, the number of paid-for daily newspapers in Africa increased by 21 percent, from 361 in 2004 to 462 in 2008. In the same period, the total average circulation of dailies increased from 8.64 million (2004)

The International Encyclopedia of Communication, First Edition. Edited by Wolfgang Donsbach. (c) 2010 John Wiley \& Sons, Ltd. Published 2010 by John Wiley \& Sons, Ltd. DOI: 10.1002/9781405186407.wbieca033 
to 14.62 million (2008). The number of free daily titles in Africa increased from 1 in 2004 to 5 in 2005, a 400 percent increase (World Association of Newspapers 2009). Today's rapid growth of the African media belies the fact that these mass media are recent and that they were mainly introduced during the colonial era.

\section{PRINT MEDIA}

One of the most obvious features of Sub-Saharan African media is the way print media were introduced in different parts of the region. The press in English-speaking West Africa was the earliest in Sub-Saharan Africa. The Royal Gazette and Sierra Leone Advertiser, first published in 1801, appear to be the region's oldest newspapers. The Royal Gold Coast Gazette (published in 1822, in present-day Ghana) was founded by Charles L. Force, a former American slave, who had previously established the Liberia Herald in 1820. Missionaries also introduced $\rightarrow$ newspapers to Sub-Saharan Africa, a good example being in 1859, when they started Nigeria's first newspaper, Iwe Thorin, in the Yoruba language. Factors that led to a viable early newspaper sector in West Africa included the presence of a large population that was western-educated and the absence of a colonial settler population that could undermine the development of the press in West Africa, as it did in other regions of Africa.

By contrast to patterns in West Africa, in Anglophone Southern and Central Africa, the press was largely introduced by European settlers. By the time the Cape Colony's administration passed the 1828 press law, the press was already 28 years old. The law stipulated that press operators were to deposit 300 pounds plus the equivalent sum in guarantees and then they were free to publish, subject only to libel laws (Bourgault 1995; $\rightarrow$ Libel and Slander). The most notable newspapers at this time included the Cape Argus, founded in 1857. In 1881, Cecil John Rhodes bought the controlling interests in the Cape Argus, using his vast wealth to grow it into a major newspaper chain expanding northward through South Africa, into Southern and Northern Rhodesia (now respectively Zimbabwe and Zambia). The Argus Group and other mining concerns established the Bantu Press in 1931 to channel indigenous African views from politics and keep an opposition press from developing in Southern and Central Africa.

The beginnings of the press in East Africa were not different from other parts of Africa. It was largely created for its settler population. The first paper was established in the Kenyan coastal city of Mombasa in 1902 by a member of the Asian community, A. M. Jeevanjee. From 1910 it was operated from the mainland under the title the East African Standard, which still exists today. In 1930, Jeevanjee established the Tanganyika Standard in Tanganyika (now Tanzania) and much later set up the Uganda Argus in Kampala. The Standard papers' rivals in East Africa included the Nation Group, owned and financed by the Aga Khan of the Ismail Islamic sect. The Daily Nation and the Sunday Nation began publishing in 1960. The Indian community in East Africa generated enough wealth from trade to be able to produce a chain of papers, an undertaking that was beyond poor, indigenous East Africans.

The French colonial administration in Africa actively discouraged the development of the press in the colonies. A heavy tax was placed on imported newsprint and printing 
machinery. The French, in keeping with their policy of assimilation of Africans into French culture, preferred to freely circulate newspapers produced in the metropolis to their African colonies. It was much later, in the 1930s, before citizens who were deemed to be in good standing with the French colonial authorities were allowed to publish in the colonies. The few African-owned papers established to serve white settler interests included Le Reveil du Senegalais, Le Petit Senegalais, and L'Union Africane. Le Gri Negre and La Phare du Dahomey, set up in the 1920s in Dahomey (now Benin), are examples of papers that were published outside French rules (Bourgault 1995). Most basically, a distinction can be made between the underdeveloped and underresourced press system in Francophone Africa and the relatively and technically strong settler press model in Anglophone Southern Africa.

\section{RADIO}

The introduction and organization of broadcasting closely followed colonial political and administrative systems. Radio was introduced in the 1920s, first in South Africa, and then developed further in 1927, when the British East Africa Company began a $\rightarrow \mathrm{BBC}$ relay service for settlers, broadcasting from Nairobi, Kenya. In 1932, the British established the Empire Service, designed to serve their colonies and dominions, including Anglophone Africa. This service relayed the BBC from Salisbury, Southern Rhodesia (now Zimbabwe) in Southern Africa and from Lagos, Nigeria in West Africa. The Nairobi service broadcast in local languages (Kikamba and Kikuyu). The Accra, Gold Coast (now Ghana) radio service, which was started in the mid-1930s, had additional relays in Sekondi, Kumasi, and Korofidua. Not only did the service have African personnel, but by the 1940s it was broadcasting in Eve, Twi, and Hausa. The British deliberately promoted the use of local languages in an attempt to build an African audience. The British spread radio to most of Anglophone Africa by the early 1940s.

The French, unlike the British, who wanted to provide something of a public service to their colonies, pursued an entirely different policy and initially delayed the start of broadcasting in their colonial territories. Radio broadcasting started in French Africa in 1931 in Madagascar, with Radio Dakar established in 1939 in Senegal. French colonial policy of direct rule was mirrored in broadcasting, as all programming was initially French in orientation and in delivery. Broadcasting served French citizens and underscored the value of colonial rule among French elites. In the Belgian Congo (now the Democratic Republic of Congo), the Jesuits at Albert College in Leopoldville (now Kinshasa) established in 1937 a small-scale radio station, broadcasting in French for two hours a week on Sundays and holidays. In 1939, a radio engineer, J. Hourdebise, began a private station called Congolia, which provided daily services in French but also in Lingala, Swahili, and Chiluba. The Belgians left broadcasting to private individuals or religious groups. In both the French and the British colonies, radio was from the outset an arm for colonial policies. 


\section{THE TELEVISION AGE}

The television age came to Sub-Saharan Africa in the late 1950s, which was the end of colonial rule for many countries in the region. Elite and urban in character, television depended on foreign programming and was initially used mainly for entertainment purposes. The medium was introduced in Ibadan, Nigeria, in 1959 and also later in Enugu, resulting in the country having two television stations before it gained independence from Britain in 1960. Other Sub-Saharan African countries that got television before national independence include Kenya, Zambia (Northern Rhodesia), and Zimbabwe (Southern Rhodesia), but it is important to stress that these early television services were mainly targeted at the white settler communities. Countries that got television after independence in the early to mid-1960s include Sierra Leone, Burkina Faso, Sudan, Gabon, Cote d'Ivoire, Congo, Niger, Senegal, Madagascar, Ghana, Djibouti, Equatorial Guinea, and the Democratic Republic of Congo (Zaire). Ethiopia and Liberia, two countries that were never colonized, also got television at this time.

It ought to be mentioned that some Sub-Saharan African countries resisted television for many years. These include Namibia (formerly South West Africa), which introduced the medium in 1981, and also Mali, the Seychelles, and Somalia, which created their services in 1983. Burundi did not have television until 1984. Cameroon and Chad delayed television until 1986 and 1987, respectively. In Southern Africa, South Africa resisted television until 1976, because of what was seen by the apartheid government as its "morally corruptive" influence and fears that it could provide information that would strengthen anti-apartheid forces ( $\rightarrow$ Cultural Imperialism Theories). Lesotho did not have television until 1988 and nor did Botswana until 1989. Television was introduced to mainland Tanzania and Rwanda in the 1990s. Malawi launched its first national television station in January 1999 and Botswana did the same in July 2000. However, for most countries in the region, the television age coincided with national independence but the medium sadly remains a symbol of national status that hardly goes beyond the major African cities ( $\rightarrow$ Television for Development).

\section{INDEPENDENCE AND DEMOCRATIZATION}

Although colonial media were used to suppress and misinform Sub-Saharan Africans, alternative media also helped them achieve political independence in the 1960s. African nationalists, such as Nigeria's Nnamdi Azikiwe, Ghana's Kwame Nkrumah, and Malawi's Kamuzu Hastings Banda, used the media to articulate their ideas about national independence. As a way of dealing with resistance from colonial authorities, these African nationalists adopted various strategies, including going underground with the press and its liberation rhetoric through pamphlets, tracts, clandestine radio, and word of mouth, known under different names in different parts of Sub-Saharan Africa (Nyamnjoh 2005; $\rightarrow$ Activist Media; Advocacy Journalism). The push for African independence in the late 1950s and 1960s was partly aided by economic and geopolitical changes that took place after World War II and also by the attempts to liberalize colonialism by the colonial authorities. 
Post-independence media systems were close to one-party systems $(\rightarrow$ Partisan Press; Party-Press Parallelism). The reason was that, once in power, these nationalist governments expanded their mass media systems and, with the help of UNESCO and bilateral aid organizations, they experimented with the ideas of development and modernization using the mass media ( $\rightarrow$ Development Communication: Africa). In the processes of nation building, the ownership and control of broadcasting was more centralized than that of print media. To a large extent, some of the previously westernized communication models and media systems were indigenized after independence. For example, in Zaire under Mobuto Seseseko, the media were nationalized and newspaper titles were changed. In many countries, British and French models of broadcasting, and to a lesser extent print media and journalistic practices, were nationalized and attempts were made to localize $\rightarrow$ media policies.

For example, most media policies in Sub-Saharan Africa, certainly in Tanzania and Zambia, prioritized radio over other mass media because it had more resonance with local life. This is particularly true of television, which largely depends on programs produced in western countries. African independence also saw increased attempts by the new states not only to own but also to control the mass media. State $\rightarrow$ censorship and persecution of journalists ( $\rightarrow$ Violence against Journalists) increased as weak African governments sought to suppress criticism from the media for much of the period after the 1960s. African journalists are poorly paid and most media organizations are underfunded. On the whole, the legacy of western notions of media culture and practice is yet to be adequately reformed in order to address the expectations of the majority of Africans, especially those living in rural Africa.

In the 1990s, the changing African media became central to the new struggle for greater political and economic independence. In response to demands by international and local pressure groups, more and more African countries opened up their media and telecommunications sectors. Before 1990, only a few African countries allowed commercial or nonstate radios; for example, Africa No. 1 in Gabon, Radio SYD in Gambia, Radio ELWA in Liberia, and Trans-World Radio in Swaziland. By 2005, most countries had opened up their broadcasting sectors after many years of state monopoly of the sector.

The 1990s ushered in a boom in private, local, community, and commercial radio stations in some regions, for example in West Africa, where 76 stations were established in less than 5 years up to 1996 ( $\rightarrow$ Community Media). In Burkina Faso and Mali, most of these new stations are in rural areas and are of a nonprofit public service character. Other countries that have allowed private broadcasting include Uganda, Rwanda, Burundi, Zambia, Namibia, Senegal, and Botswana. After majority rule in 1994, South Africa made huge efforts to reform and democratize the South Africa Broadcasting Corporation $(\mathrm{SABC})$ into a genuine public service broadcaster. The country has also opened up its media sector greatly. By contrast, Zimbabwe is one of the countries that is yet to open up its broadcasting sector, and for much of its period of independence from Britain, since 1980, it has been less tolerant of private media. For example, in September 2003, police in Harare stormed the offices of the Daily News and shut the "opposition" newspaper, ostensibly banning it for refusing to register with the government-appointed Media Information Commission (MIC). In general, a wave of democracy in the 1990s 
brought with it multipartyism and a degree of media pluralism in many Sub-Saharan African countries.

\section{INTERNET AND MOBILE COMMUNICATION}

From 2000 to 2006 the percentage of $\rightarrow$ Internet users in Africa grew 625.8 percent, with the bulk of Sub-Saharan African users in South Africa (5.1 million), Nigeria (5 million), Sudan (2.8 million), Zimbabwe (1 million), and Kenya (1 million). According to the 2006 World Development Indicators of the World Bank, the number of mobile phone subscribers in Sub-Saharan Africa rose dramatically from 7.5 million in 1999 to 76.8 million in 2004, and between 2000 and 2004, fixed-line and mobile phone subscribers increased from 31 per 1,000 to 84 per 1,000. This growth was mainly driven by a 400 percent increase of mobile phone subscribers in the region. Four times as many people had access to mobile phones as to fixed-line phones in Sub-Saharan Africa in 2004 (World Bank 2006), making Africa the first place where mobile subscribers outnumber fixed-line subscribers.

Although spectacular growth has been achieved in the mobile phone and Internet sectors, the overall picture in Sub-Saharan African countries seems to suggest that a very small group of privileged Africans have benefited. For example, in 2009 there were 86.22 million African Internet users (8.7 percent of the African population, about 4.8 percent of users in the world) in a continent with an estimated population of 991 million (14.6 percent of the world's population; $\rightarrow$ Digital Divide). However, one needs to be skeptical of these figures, not only because of the efficacy of methods used to generate the statistics but also because of their failure to reflect multiple user dimensions, of say mobile phones, which are prevalent in Africa.

\section{THE TWENTY-FIRST-CENTURY AFRICAN MEDIA SYSTEM}

Regulatory and technological issues dominate the twenty-first-century African media system. There are increased calls and moves toward more diverse media frameworks. State monopolies have been undermined by a wave of deregulation, commercialization, and privatization of broadcasting and telecommunications. Demands for democratic changes have included calls for the democratization of the media spaces, and technological changes have increased technical options, allowing plurality in the telecommunications and broadcasting sectors ( $\rightarrow$ Communication Technology and Development).

A small but significant number of Africans is now able to receive popular radio and television content via terrestrial, satellite, cable, and Internet. Most countries are taking advantage of the rapid development of new communications technologies and digitization. For example, Cameroon and Mozambique now also use the capital-intensive cable television format. South Africa's Multichoice Digital Satellite Television (DSTV), a digital subscriber management company and the first pay-TV service in Sub-Saharan Africa, grew from M-Net, a single channel pay-TV service that was set up in South Africa in 1986. By 2002, Multichoice was providing 55 TV channels and over 40 audio 
channels for a monthly subscription of US $\$ 45$. In 2006, Multichoice was part of a group of big players in African broadcasting that include the BBC and Canal France International (CFI), which provide free-to-air networks delivered by satellite to local African television stations, which then broadcast the channels in whole or part. The networks are CFI, which styles itself as a program bank, and Africa Broadcast Network (ABN), which grew from program distributor $\mathrm{ABC}$ and TV Africa and received financial backing from the International Financial Corporation in 2001. In 2003, ABN broadcast one-hour prepackaged programs, typically consisting of American programs, to Ghana, Kenya, Zambia, Nigeria, and Tanzania $(\rightarrow$ Digital Media, History of; Satellite Television).

Sub-Saharan Africa has also seen a dramatic growth in the indigenous entertainment production industry. For example, the burgeoning video film industry in Nigeria, now dubbed "Nollywood," has become African's answer to India's $\rightarrow$ Bollywood and America's $\rightarrow$ Hollywood industries. Rapid technical developments and affordable equipment are giving Africans a chance to produce and consume their own images. Internet radio stations, online newspapers, and digital music libraries are set to continue revolutionizing the Sub-Saharan African media scene ( $\rightarrow$ Online Media). However, the point can be made that the evolution of the African media system currently works in favor of new market-based operators, which are not producers but peddlers of foreign-produced content, within the parameters defined by colonial legacies. Information for citizenship is minimal in media diets that are urban-biased and market-driven. To sum up, SubSaharan Africa's emerging media system is diverse and fast growing but to a large extent is still influenced by its colonial legacy.

SEE ALSO: $\rightarrow$ Activist Media $\rightarrow$ Advocacy Journalism $\rightarrow$ BBC $\rightarrow$ Bollywood $\rightarrow$ Censorship $\rightarrow$ Communication Technology and Development $\rightarrow$ Community Media $\rightarrow$ Cultural Imperialism Theories $\rightarrow$ Development Communication: Africa $\rightarrow$ Digital Divide $\rightarrow$ Digital Media, History of $\rightarrow$ Educational Communication $\rightarrow$ Hollywood $\rightarrow$ Internet $\rightarrow$ Journalism $\rightarrow$ Libel and Slander $\rightarrow$ Media Economics $\rightarrow$ Media History $\rightarrow$ Media Policy $\rightarrow$ Newspaper $\rightarrow$ Online Media $\rightarrow$ Partisan Press $\rightarrow$ Party-Press Parallelism $\rightarrow$ Political Communication $\rightarrow$ Radio $\rightarrow$ Satellite Television $\rightarrow$ Television $\rightarrow$ Television for Development $\rightarrow$ UNESCO $\rightarrow$ Violence against Journalists

\section{References and Suggested Readings}

Article 19 (2004). Broadcasting policy and practice in Africa. London: Article 19.

BBC World Service Trust (2007). Africa Media Development Initiative (AMDI). At www. bbcworldservicetrust.org/amdi, accessed August 3, 2007.

Bourgault, L. M. (1995). Mass media in Sub-Saharan Africa. Bloomington, IN: Indiana University Press.

Fardon, R., \& Furniss, G. (eds.) (2000). African broadcast cultures: Radio in transition. Oxford: James Currey.

Honeyman, R. (2003). African regulation of satellite broadcasting in the era of convergent ICTS. In Broadcasting policy and practice in Africa. London: Article 19, pp. $71-113$.

Internet World Stats (2009). Internet usage statistics for Africa. At www.internetworldstats.com/ stats1.htm, accessed 3 May, 2010. 
Kasoma, F. P. (ed.) (1994). Journalism ethics in Africa. Nairobi: ACCE.

Mytton, G. (1983). Mass communication in Africa. London: Edward Arnold.

Mytton, G. (2000). Sub-Saharan surveys: From saucepan to dish-radio and TV in Africa. In R. Fardon \& G. Furniss, (eds.), African broadcast cultures: Radio in transition. Oxford: James Currey.

Nyamnjoh, F. (2003). Media pluralism and diversity: A critical overview of competing models. In Broadcasting policy and practice in Africa. London: Article 19.

Nyamnjoh, F. (2005). Africa's media: Democracy and the politics of belonging. London: Zed Books. Ronning, H. (1994). Media and democracy: Theories and principles with reference to an African context. Harare: Sapes.

Wedell, G. (ed.) (1986). Making broadcasting useful: The African experience. The development of radio and television in Africa in the 1980s. Manchester: Manchester University Press.

World Association of Newspapers (2009). Shaping the future of the news. Paris. World Association of Newspapers and ZenithOptimedia.

World Bank (2006). World Bank indicators 2006. Washington, DC: World Bank. 